\title{
Difficulties and Challenges Facing Strategic Planning in Jordanian Municipalities; Applied Field Study from Managers Point Views
}

\author{
Saleh A.A Tamimi, Assoc. Prof. Dr. Samihah Khalil, Prof. Dr. Haim Hilman Abdullah \\ Universiti Utara Malaysia
}

Correspondence Author: Saleh A.A Tamimi, Universiti Utara Malaysia

Received date: 12 June 2018, Accepted date: 4 September 2018, Online date: 13 September 2018

Copyright: (C) 2018 Saleh A.A Tamimi, et al, This is an open-access article distributed under the terms of the Creative Commons Attribution License, which permits unrestricted use, distribution, and reproduction in any medium, provided the original author and source are credited.

\begin{abstract}
The objective of this research paper is to examine the challenges facing Jordanian municipalities organizations in Strategic Planning (SPing). Current paper relies on descriptive technique and is subject to theoretical literature review in Strategic Management (SM) field, it's a qualitative research paper used thematic analyses approach based on semi-structure interviews with municipalities leaders or key managers. The structure of this paper starts with introduction, followed by study background, then a presentation of SPing challenges results and analysis and the implications, finally this paper ends with conclusion and recommendations. This investigation question is; "What are the difficulties and challenges that encounter Jordanian municipalities managers in SPing for their organizations?". The answer of this investigation is being based on municipalities key managers views and SM theory within Public Organization (POs), also it incorporates the analysis of other related literature to draw better conclusions. The significance of this work comes from the importance of SPing in this area at the current time, where it is one of the first studies in Jordan Municipal sector. However, this paper will rely on interviews collected data and it will be limited to the targeted municipalities interviewees views, but it uses and incorporate other academics works and expertise from all over the world for explanations and in taking out some valuable lessons. Findings indicate that only large municipalities have a sort of SPs in different degrees or values, while small and medium size municipalities rely on operational plans issued by the Ministry of Municipal Affairs (MMA), also findings showed that all municipalities are facing numerous challenges and difficulties in this management vital process. Finding shows that municipalities are struggling with their SPs formulation from various factors to include inside and outside factors. While, most municipalities mayors or key managers were aware of SPing available tools, and they revealed that SPs has a positive effect on their municipality's performance and outcome services.
\end{abstract}

Key words: Difficulties and Challenges; Strategic Planning; Jordanian Municipalities; North Region.

\section{INTRODUCTION}

In spite of Jordanian local administrations or municipalities great achievements and changes in the last two decades, Strategic Planning (SPing)in Jordan municipalities still faces many obstacles and challenges in terms of strategy formulation or SPing (Abu-Kharmeh\& Abu-Alsondos, 2011; Shuqair, Abdel-Aziz, 2015; Saif, et al, 2004; Omar, 2017, June 17). Which led to expand the development gap between provinces and enlarged the decline in their services(Ma'ayta, 2016; Mansur, 2014, December 1).Yet, region instability consequences and its overlapping with other internal issues or factors had complicated the Jordanian municipalities working environment and exaggerated these problems and challenges (Gause, 2011; World Bank, 2017, June 13). Bryson (1999) affirmed that public managers are largely influenced by world changes, as countries became more interconnected and influenced by each other. He stated that; "changes on one place can echo unpredictably and often dangerously in other places". This explain part of the complications created Jordanian municipalities SPing challenges and difficulties.

While, SPing is one of the crucial key elements for organization development (Ktameen, 2009; Elbanna\& Fadol, 2016). SPing develops long-term planning capabilities and motivates future thinking to enhance organizations performance (Bryson, 2018; Mintzberg,1987).It provides guidelines to enlighten the organization future path, which assure the continuation of POs feasibilities and capacities(Poister, Edwards, Pasha, \& Edwards, 2013). Hence, SPing is an important driver for organization strategy and performance, it is the core of the inclusive modern management (Rasche,2007; Meier, O'Toole, Boyne\& Walker,2006). Though, it is linked to top management(Athapaththu, 2016), but it's also a collective effort and its activities related to all stakeholders or management levels (Hunger\& Whaleen, 2003). It contributes in avoiding surprises and reduces the losses. Its importance in the municipal work is impeded in the right thinking about the future (Poister \& Streib,1999).

Hence, we recognized SPing importance and its role in POs including municipalities, we realize that the challenges facing SPing within public-services are not only technical, but they are more inclusive and complicated, as these challenges are linked with many other internal and external factors such as; legislations, policies, participant proficiencies and skills, organization structure, cultures, resources availability, and any other related management issues (Musa, Sheen, 2017; Shah. 2006), considering that there are some other challenges come from the nature of SPing in public administrations.

Therefore, this research paper is focused on investigating the difficulties and challenges facing Jordanian municipalities SPing. This inquiry aims to find answers to; "What are the difficulties and challenges that encounter Jordanian municipalities managers in SPing for their organizations?". The researcher adapted qualitative approach to answer this inquiry and followed thematic analyses approach to analyses SPing difficulties and challenges. While, the research community consists of Jordan Northern Region municipalities, which comprises a total of 46 municipalities, represents $46 \%$ of all Jordanian municipalities. This study is based on semi-structured interviews with (15) municipalities officials or key managers, based on pre-prepared interview guide, and its focused on large 
Citation: Saleh A.A Tamimi, et al., Magnetic Basement Depth and Structure over Parts of Bida Basin Nigeria with Evidence from 2-D Spectral Analysis and 3-D Euler Deconvolution. Australian Journal of Basic and Applied Sciences, 12(9): 122-127. DOI: 10.22587/ajbas.2018.12.9.20

municipalities. Luckily, all targeted interviewees were available (100\%), this represented excellent response rate (Mugenda, 2003). Interviews were scheduled for one hour long followed by a short conversation as recommended by other scholars (Elbanna, 2013; Poister, 2005). Additional visits and personal conversations were conducted to validate the collected data. Still Jordanian municipalities have many obstacles and challenges regarding SPing processes (Saif, Suliman \& Tal, 2004; Jaradat, Taamnh, 2005; Harahsheh, Alhbees, 2010). While, this study focused on difficulties and challenges facing municipalities mangers SPing activities.

\section{Back Ground:}

Local administrations law in Jordan issued in 1921, it had many changes overtime to face the upcoming challenges of these administrations (Ma'ani, Abofars, 1995). While, SPing had been induced in Jordanian public administrations since 1950s (Shuqair, Abdel-Aziz, 2015). Besides, SP is considered the most essential component for SM existence, it's the main driver for organizations management success and development (Bryson, Crosby \& Bryson, 2009; Yassin, 2011).

Currently, there are (100) municipalities and 12 governorates (12 largest municipalities) in the state of Jordan, these local administrations are located in three regions; North, Central, and South (MMA Yearly report 2016). While, municipalities are classified in three levels or tiers based on their population size and locations (Tier-I/ large, Tier-II/ Medium, and Tier-III/ Small). North Region includes 46 municipalities;(4) municipalities tier-I or large municipalities ( Namely; Irbid, Jerash, Mafraq, Ajloun), and (42) municipalities tier- II\& III(Ministry of Municipal Affairs (MMA) Yearly report 2016).

Whereas, government in Jordan as mentioned before had encouraged local administrations to produce formal SPs, as its essential document for all Jordanian public organizations including municipalities (Jordanian Municipal Law 2017, Article Five). As, official SPing has positive relationship with strategy implementation and the overall organizations performance (Elbanna, Andrews\& Pollanen,2016). Therefore, Jordanian legislator focused on the principles of SP in POs to trigger and stimulate the overall public management system. Putting in mind that the possibility of SP occurrence increases with the organization size and intent to change or develop the organization management operations (Debarliev \& Trpkova, 2011; Mercer,1991), but SPing suit all organizations sizes and types or nature (Butnaru\& Balcan, 2012; Magrebi, 1999). However, Jordanian legislator didn't even give enough details to grantee the effectiveness of SPing in these municipalities, Consequently, the responsibilities and functionalities of these plans suffers from may shortfalls and malfunctions.

Nevertheless, Jordanian state urges SPing practice at all local administrations levels; Governorate (Muhafaza) and Municipal Levels (Klyla, 2013).Whereas, municipalities have a key and dynamic role in Jordanian public services and the have a vital social responsibility that affects various development aspects of the state economy(Klyla, 2013; Ma'ani, Abo-fars, 1995; Gazawi, 1996).

3.Results and Analyses:

The researcher relied on the direct answers of the interviewees involved in SPing, and available related documents. Participants were asked about the challenges and difficulties facing them in SPing and strategy formulation processes for their organizations. The researcher found that all municipalities almost suffer from the same types or nature of problems at this management stage, although they were expressed in different ways, and they suffer from these issues relatively in various degrees, but this due to the different conditions or environments for each municipality. Accordingly, the researcher has extracted a large number of problems and challenges, after then thematically classified and present them in such a way, to facilitate the understanding of their nature and how to deal with them. This makes it easy to figure out the nature or type of the problems and the party concerned to resolve or tackle these issues.

Basically, the researcher found that there are no special sections for SPing in these municipalities structures, and no SPs in tier II \&III (small and medium) municipalities sizes, also there are no dedicated training or syllabus tailored to this functionality. While there are s sort of SPs in Tier-I (large) municipalities. Though, all municipalities should have produced written and up to date SPs, as the Jordanian legislator stipulated that municipalities should issue written strategic plans regardless the level or size. But he ignored the need for planning section or staff with special training and competencies to perform this role. Therefore, the researcher focused on large municipalities and some officials incharge from the MMA and related Local Governments. It was found that SPing task was assigned to more than one department which are; the Directorate of Planning and Studies, and Directorate of Development and Investment and in some cases more than these departments. This interference and dual roles for these departments had complicated municipalities planning or strategy formulation process and disturb this functionality, as it caused interferences and conflicts between these departments or managers responsibilities or interests.

Nevertheless, public mangers or leaders require a suitable scientific approach to assist them in managing their current changing environment, as they are now more accountable to their organizations performance and own communities than ever before (Bryson, 1999). This accountability and commitment require a dedicated and qualified sections or managements bodies to institutionalize this management work, and it should clarify municipalities managers responsibilities and their related departments functionalities. Despite the fact that SPing is the most suitable management tool to deal with the turbulence environment, as it's the discipline approach to produce and articulate organizations decisions or actions in a pre-prepared strategy (Armstrong, 1982; Bryson, 2018), but this tool or technique required a foundation base within the municipal organizations structural to clarify and control these decisions discipline approach process. As, SPing process has a constructive nature procedure from one side and a productive and positive influence on POs management and performance on the other side (Boyne, 2001; Mercer, 1991).

However, SPing is existed in some Jordanian POs such as; Public Universities for example (Al-Awawdeh, 2017). While, other results in Jordanian public sector showed that SPing success is essential for government reform and POs performance, and there is appositive relation between these two notions (Azahari, Mustafa \& Yusoff, 2017). But, Jordanian municipalities still having many challenges in in SPing issue. It is related to these organizations both external and internal factors aspects such as; legislations, economic factors, organizations structure factors, municipalities functionalities, and other issues associated with their chain of commands relations within the Jordanian overall municipal structure. However, SP in POs by its nature has many difficulties and challenges (Mercer, 1991). Which complicated Jordanian municipalities planning role and made them unable to play their planning activities effectively and efficiently in some respects.

Whereas, in Jordanian business sector, Dudin, (2013) exhibited that there were significant differences in managers attitudes towards SM challenges, also he noted that SM term were replaced by long-term planning. Which indicate clear interest in SPing within this sector. While, Aldehayyat and Anchor (2008) findings assured that there is more interest in SPing at the businesses organizations, and his results showed that managers were trained and aware of most SPing available tools and techniques. Besides, these existed tools and techniques in Jordan private-sector were similar in nature with other countries existed SPing tools and techniques such as Czech Republic(Afonina\& Chalupský 2012).

Putting in mind that some scholars argued that planning issues or difficulties are more technical problems such as; lack of suitable resources and competencies...etc. than political matters or other planning nature problematic issues (Boyne, Gould-Williams, Law\& Walker, 2004). So, the researcher focused more on SPing technical perspectives and other related issues. Yet, Jordan municipalities still encounter various aspects of difficulties and challenges in their SPing capabilities, these findings are as follows:

1. Municipality's major challenge in SPing is that municipalities don't have a dedicated planning section or department, which grantee to institutionalize the process of SPing. Jerash Municipality Mayor stated that municipalities structure must include SPing section. He assured that all planning departments and efforts must be unified in one unit, so this will assist to institutionalize SPing at the municipal level, and it helps in gaining accumulative experiences benefits. This result is also compatible with other municipalities results from Irbid and Ajloun municipalities. While, these findings are in line with Al - Qayq (2015)conclusions and findings, that municipalities should establish strategic development planning departments within their municipal structure, as these units will institutionalize SPing and assure the implementation of municipalities functions development.

2. Municipalities depend on executive or operational plans come from the MMA, or rely on assigned fragmented " fractional" or operational plans based on short-term objectives as a realistic alternative to strategic plans such as: municipalities annual budget plan or other working plans imposed by the ministry or other 
Citation: Saleh A.A Tamimi, et al., Magnetic Basement Depth and Structure over Parts of Bida Basin Nigeria with Evidence from 2-D Spectral Analysis and 3-D Euler Deconvolution. Australian Journal of Basic and Applied Sciences, 12(9): 122-127. DOI: 10.22587/ajbas.2018.12.9.20

authorities; Municipalities budgets always come in a form of executing or working plans with its own annual objectives, and the financial support required for the execution of these objectives. Irbid Mayor affirms that ministry decisions and interferences is one of the main challenges for their SPing process, and he stated that the ministry had converted the municipalities organizations into implementation tools. While, West-Irbid municipality Mayor ( Tier-II Municipality)affirmed that the don't have even strategic plan, because they depend mainly on the operational plans comes from MMA. While, Mafraq Executive Director and the Local Government Development Unit Director said that; municipality relay on fragmented or short plans for many reasons, but they said that most important is the situation in the neighboring countries and its impact on their working environment in Mafraq case. However, they added that this in addition to other issues they originally face which have forced them to rely on the fragmented or operational plans, these fragmented plans come from their ministry or from international or local donors sometimes. Whereas, the researcher believes that there are two main factors responsible for this issue which are; First, the existence of operational plans come with their annual budget or some other specific projects come for refuges assistants from donors. Second, is the fact that some municipalities shortterm plans might help mayors and municipalities elected council to achieve their personal agenda and satisfy their electoral-base demands, as it is easier to be modified to serve personal objectives; For example, the mayors and the new elected members are trying to set short-term goals to match them with the annual budget to satisfy the electoral base and shows speed of response, these issues are on the cost of strategic objectives in most cases. While, other key-managers side that this issue is due to the fact that in the last few years there were many changes in the legislations and municipalities laws which confused the municipalities managements and make them unstable and don't have enough dependency to be able to plan for themselves. The researcher sees that all of these changes, interferences, and environments difficulties had helped to transfer these municipalities into implementation parties regardless their size, and MMA interventions had limited municipalities stakeholders' participation in this process, especially if we know that the ministry does consider some factors in the municipalities characteristics and other related issues. Basically, ministry considered factors or issues is not derived from each municipality actual environment. However, even if the ministry consults the municipalities, this consultation is not binding on the ministry. This processes or interventions contradicts Johnsen (2017) results concept; Johnsen, (2017) result showed that shareholders involvement in SPing has some positive impacts on POs performance. Though, Abo Naem, 1994, stated that municipality management have the tendency to focus on the short-term goals, which leads to loss track or even miss the organization or municipality strategic objectives.

Nevertheless, when the researcher wanted to understand the cause of these issues from the MMA officials' perspectives, he asked the concerned officials in the MMA namely; the Assistant Secretary-General for Municipal and Rural Affairs and Assistant Secretary-General for Planning. Both officials' answers explicated that the reason is the weakness in municipalities planning capabilities and their inability to plan and resource their own objectives, as well as the researcher felt that there is a lack of confidence of the municipalities for other various reasons from the ministry respondents' perspectives. While, the municipalities mayors and key managers see the above issues otherwise, and they insist that even though they have some problems in this regard, but still they claim that they can do the job by themselves, and they insist that municipal law in this regard should be activated on both sides (MMA and Municipalities). However, the researcher agreed that there is a need to activate the law more properly, but he sees that there is a need to develop sufficient instructions and regulations to clarify the legislations for SPing formulation and implementations processes procedures, these instructions should include all necessary details for all parties to cover the overall stages of this process, whereas he feels that municipalities need capabilities building in this regard too. So, this process should be implemented in a comprehensive package of reforms that includes two main axes; First axis, rehabilitation of the municipalities in terms of training and rehabilitation to increase their capabilities to rely on themselves (self-sufficient) and work independently with positive participations in this planning process.

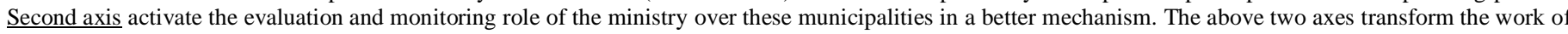
both parties (ministry and municipalities) to more institutionalization and less interferences or interests conflicts in their functionalities and responsibilities. It also reduces the impact of personal bias factors on the municipal work.

3. The nature of the municipalities role and the status of the existed laws and legislations limited the ability of the Jordanian municipalities to set their own strategic objectives, such as the legislator sets the duties of the municipality in details which limits the municipalities space to formulate their own strategic objectives, it also has many other determinants to develop the municipality mission and limit their abilities to settle their own vision. For example, The Mayor of Irbid and Ajloun Executive Director stated that the municipality mission is fix and it doesn't change. Also, the municipal law stipulates that the municipalities strategic objectives must be consistent with the state national goals and objectives. These such issues reduce the area of maneuvering for municipalities managers in characterizing their own organization objectives and hinder them from choosing the most appropriate strategies. Thus, this might limit municipalities administrations role to execution nature to more extent. Abo-Naem (2002a) stated that when legislator sets out municipalities mission and objectives without their participation, it sometimes leads to objectives ambiguity. However, these objectives might change over time or vary in response to some organizations environmental constraints. So, the legislator confines the role of municipalities management servant to a limited role. Consequently, this will limit their managers strategic thinking ability, and weaken their capability in creating well-structured SPs. In addition to the above, Jordanian municipalities suffer from laws frequent changes in recent years, Jerash Mayor stated that one of the main challenges for their current SPing or even formulating their current strategy is the frequent changes of the municipal laws in the last few years. Which confuses their work and compel them to work with short-term or operational plans. These plans activities are based on projects-managements and daily business operations, rather than having their own long-term planning motivations.

4. Lack of the necessary resources availability and distribution suitability to achieve these municipalities various roles; services duties, development role, investment role, and their role to resolve the unemployment issues within their area of responsibility, this in addition to other issues related to their dependency. All interviewees agreed that resources availability and their dependency issues are the main challenges for their SPing. While, Ajloun municipality Executive Director and his Development and Investment Department Director stated that their financial resources are even not enough to pay their staff salaries, and "they were wondering how come they will plan for their organizations". While, each of the above roles needs its own resources and specific capabilities and authorities to execute them. Yet, the researcher believes that in the nature of municipalities roles and their high dependency on the government policy is a challenge by itself, and it add more complexity and difficulties on the municipalities SPing, But that doesn't remove their capabilities nor relieve them from their responsibilities.

5. Lack of professional managerial competencies that have the ability to think strategically and conduct SPing in these municipalities management staff, which is a necessary condition for SM existence or practice; $100 \%$ of the targeted key managers interviewees agreed that they have a real problem in employing the suitable competencies. As well as all interviewees mayors and executive mangers stated that they don't have a suitable rehabilitation and training syllabus tailor to their municipal work duties and functions. As they are not assigning or retaining the suitable competencies, but instead these municipalities managements are filling vacancies by mood (WASTA or MAHSOBIA) and interpersonal relationships in most cases, because of lack of a clear functional profile or municipalities jobs vacations descriptions, and some negative dominated cultures from the other side. Although, recently the MMA has subjected the appointment in these municipalities to the Civil Service Bureau Department, which is supposed to solve part of the current problem. But the researcher found that it is necessary to deal with the current issues and its current implications in a clear methodology for both the municipalities and the Ministry of Municipal Affairs, which the researcher didn't notice any positive practical steps in this direction.

\section{Implications:}

However, the above results indicate that Jordanian municipalities face a real challenge in their SPing. While, SPing itself has a prominent positive role in facing municipal work future challenges and difficulties (Durh\& Jaradat, 2014). So, municipalities must attempt to avoid these obstacles or challenges and minimize their negative effects. This attempt will help these municipalities to improve their SPing process behaviors. While, improving these planning activities will leverage their performance and enhance the quality of their provided services.

Nevertheless, the concepts of the above challenges results and findings were in line with other scholars' findings such as; Galloway (1990), Mercer (1991), and Abu-Kharmeh\& Abu-Alsondos (2011) findings and results. Galloway (1990) noted that government organizations challenges are characterized by; POs have 
Citation: Saleh A.A Tamimi, et al., Magnetic Basement Depth and Structure over Parts of Bida Basin Nigeria with Evidence from 2-D Spectral Analysis and 3-D Euler Deconvolution. Australian Journal of Basic and Applied Sciences, 12(9): 122-127. DOI: 10.22587/ajbas.2018.12.9.20

the tendency to fail to agree or even lose track of the main organization goals and objectives, lack of professional training were area essentially is needed, organizational communication breakdowns in most cases, and complexity or problematic issues regarding their decision-making transparency. This necessitate a well-structured municipalities organization to have the proper organization structure and employ suitable competencies equipped with the proper training, this structure and competencies will illuminate the tendency of short-term objectives and increase the decisions transparency, as well as it will resolve the other complexity and other management problematic issues.

Mercer (1991) pointed out some areas in which strategy formulation or planning phase might face difficulties and challenges, which are; linking their own municipalities strategic plans to the central government planning activities, and the issue of linking the municipalities local strategic objectives with annual municipalities budgets objectives. While, this can be resolve through strategic planning process itself and the collaboration of all management levels. So, all shortterm or different departments objectives will be linked to the main municipality objective within the strategic plan document and funded through the proper department with the most suitable funding source. But this process required a suitable communication across the overall municipal system chain of command, to include the ministry and municipalities, so all managements functionalities will be activated and tailored to the most suitable management level.

Therefore, MMA should not set a ceiling on the authority of the Mayors or key managers on financial behaviors or other issues or municipalities essential decisions. It should assure that municipalities are complied with the municipal law in this regard, in other words ministry should practice more supervisory or evaluation and directive nature role, while municipalities practice more planning and executing nature roles as they are closer to their environment and more aware of their needs or demands. This will eliminate some of the personal and interference considerations. While, current investigation results and other scholar results indicated that there are personal consideration and interferences are influencing financial allocations and dependency, this caused a serious damage in the overall municipal performance system.

Although, SPing or strategy formulation in Jordanian municipalities faces many challenges as mentioned above, but it still plays a crucial role in these organizations future interest, and it's the bedrock for modern management and transparency existences within the municipal system, putting in mind that SPing efficiency proposes the most suitable framework for POs function at the long-term. While, to leverage the municipal work mangers should have the most proper and sufficient training and skill to handle their obligations and responsibilities. Managers ability to meet successfully environmental conditions of tomorrow revolves around their understanding of organizations as integrated and dynamic wholes (Miles, Snow, Meyer\& Coleman, 1978), which required knowledge and freedom to act. This also needs the availability and suitability of these organization cultures, structures, and resources to ensure their organizations success and advantageous (Hunger\& Whaleen, 2011; Yassin, 2011).

Therefore, municipalities managers and MMA must collaborate their effort to enhance SPing at the municipalities local level, as local planning is crucial element of municipal planning (Rudolf \& Grădinaru, 2017). Also, Guyadeen (2017) results showed that the importance of local government consolidation role in planning and it is a way of improving their quality. So, each system is based on its own foundations successes. A malfunction in one issue might cause a serious issue in the overall system, which in sum cause a serious damage in the organization performance; Seasons (2003) concluded that "monitoring and evaluation would enhance municipal planning activities". This assure the interconnectivity and dependency of all managerial levels and SM phases and their related issues and management values. While neglecting any phase or level will turn a well-structured SP sub-system into a failure and cause a serious damage in the overall SM system (Abdelkader, 2016; Al-Salm, 2005; Elbanna, 2013; Ktameen, 2009), and a cross the overall municipal managements levels.

Thus, municipalities managements should consider all SPing challenges or difficulties and fulfill all necessary factors or criterions for each element to grantee the success of the inclusive municipal management system. However, it is clear through personal interviews of municipalities key managers that municipalities SPing suffers from many problems and difficulties, which negatively impacted their planning quality. Höglund and Svärdsten indicated that when public sector does their long-term planning interpretation, they tend to become quite centralized, fixated on short-term measurements and focused on operative matters(Höglund\& Svärdsten, 2015). However, the researcher agrees with Höglund and Svärdsten, that some POs have translated SM into New Public Management (NPM) discourse, but, that doesn't change the fact that NPM was an important reform in POs managements and it supports the existence of SM in POs.

Bryson et al (2009) assured that SP is mostly viewed "as way of knowing meant to promote strategic thinking, acting, and learning; improve decision making; and improve organizational performance" (Bryson et al, 2009). This illustrate another aspect of SPing practice in POs, which assured the inclusiveness and stockholders participation encouragement. Nevertheless, some municipalities respondents consider SP is the corner stone of the inclusive SM, but they stated its time and efforts consuming; the Directors of the Development and Investment in both Irbid and Ajlun stated that one of the important challenges with the municipalities SP is the time and effort consuming, which make it difficult and costly. The researcher agreed that its time and effort consuming, but he sees that it's a continues process which save planning time and its worthy. Bryson (2004) noted that SP must be flexible process, which means it is a continuous process. And it can be updated with any upcoming data throughout the overall SM process, which must save time and reduce cost on one hand and resolve weak decisions cost implications issues. Also, Edwards (2012) findings assured that the organization performance will payback strategic planning drawbacks, throughout the overall management process. This assure the importance of SP to POs performance (Aldehayyat \& Al Khattab, 2012). As most studies assured that SPing has a positive impact in the overall POs performance, regardless its shortfalls or drawbacks issues.

\section{Conclusion:}

The situation in Jordanian public-sector and its overlapping with the changes in the region has intensified and complicated SPing challenges in Jordanian municipalities. These complicated and overlapped legal, economic, social, political, cultures, and other public management influences have affected SPing abilities and capabilities. So, these municipalities were relied on annual budget execution plans, as these plans come in as sort of operational plans or fragmented plans imposed by the ministry or other authorities or external and internal donors.

However, SPing existence suffers from many difficulties, these were mainly related to these municipalities structures, state legislatives, organizations chain of command relations, training, and resources allocation, which negatively affected SPing functionality and consequently degraded their performance. While, these issues were obvious in small and medium size municipalities (Tier II \&III); they don't have SPs and relied only on operational plans imposed on them by the MMA. Whereas, , there were some types of SPing in large municipalities (Tier I), but these large municipalities existed SPs were varied in their details and values. Also, they suffer from many shortfalls and defects in their planning process and constructions. These problematic issues caused several faults and failures in these organizations performance and originated a declined in their output services. However, most interviewees were aware of the importance of SPing tools and techniques and their positive effect on municipalities organizations performance.

\section{Recommendations:}

In order to overcome these difficulties and challenges, all leaders and key mangers especially the MMA officials must be aware of the importance of SPing, and its essential role to urge municipalities ability to perform their mission effectively and efficiently, regardless their size, as these public organizations have the same role irrelated to their size or location. This awareness should include the following; First, create a comprehensive package of legislation and procedures to clarify SPing responsibilities and guarantees the existence and application of this management tool. Second, equip all municipalities managers and leaders with enough administrative and leadership knowledge in a scientific and institutional approach, and to illustrate the importance of the collaborative preparation of strategies and policies that contribute in upgrading SPing processes in these municipalities, this to ensure the exercise of SPing by all management levels, rather than all of them are transferred to conduct the daily businesses and operational management practices, which is usually the core of the lower management work only. Third, reviewing municipalities structures and chain of command relation; this structure must include dedicated bodies or sections for SPing and implementation process in an institutional manner. Forth, create a comprehensive and clear job description to all municipalities jobs and functions, to ensure the 
Citation: Saleh A.A Tamimi, et al., Magnetic Basement Depth and Structure over Parts of Bida Basin Nigeria with Evidence from 2-D Spectral Analysis and 3-D Euler Deconvolution. Australian Journal of Basic and Applied Sciences, 12(9): 122-127. DOI: 10.22587/ajbas.2018.12.9.20

existence of adequate competences, more importantly linking all promotions and postings to this rehabilitation system. Therefore, municipalities require a more comprehensive legislations and proper rehabilitation to create some positive cultures through the adoption of mastery, sincerity, and institutional work values, which guide and control the municipal work and helps in creating a better working environment at the long run. The researcher recommends further study on the impact of the current municipal chain of command on the municipalities SPing capabilities.

\section{REFERENCES}

Abdelkader, M.A., 2016. The basics of modern SM [ Alasaseat fee aledarh alestrategeh almoaserh]. Jordan; Amman: Academic for Publishing \& Distributing Co.

Abo-Naem, A., 2002a. [Almshakl alti tahd mn tatbeek aledarat alestratejeah fee almondmat alamah bdwlt alemarat alarabia almutahdah] Problems that limit the implementation of SM in POs in the United Arab Emirates. United Arab Emirates; Institute of Management Development, Research and Consulting Department. 1-58.

Abu-Kharmeh, S.S., J.A. Abu-Alsondos, 2011. Measurement of resources allocation efficiency in the Jordanian municipalities (Case study: Greater Irbid municipality). Journal of Geography and Regional Planning, 4(2): 53-65.

Afonina, A., V. Chalupský, 2012. The current SM tools and techniques: The evidence from Czech Republic. Economics and Management, 17(4): 1535-1544.

Al - Qayq, S.F., 2015. [Door almosharka almujtamaea fee tahkeek altanmiat almustdama; alketat alestrategeah altnmoyah llmuden alflsteeniah khala derasya] The role of community participation in achieving sustainable development; The strategic development plans for Palestinian cities as a case study. Journal of the Palestine University for Research and Studies. Palestine; Gaza. Edition 8, Part I.

Al-Awawdeh, W.M., 2017. SP and Innovation: A Case Study of Jordan University of Science and Technology. International Business Research, 10(9): 159.

Aldehayyat, J., Al A. Khattab, 2012. SP and organizational effectiveness in Jordanian hotels. International Journal of Business and Management, 8(1): 11.

Aldehayyat, J.S., J.R. Anchor, 2008. SP tools and techniques in Jordan: Awareness and use. Strategic change, 17(7- 8), $281-293$.

Al-Salm, S.M., 2005. [Asasiat Al-edarh Alstrategyah] Fundamentals of Strategic Management. Amman, Jordan. Dar-Wael Publisher, 30-32.

Andrews, R., G.A. Boyne, J. Law, R.M. Walker, 2009. Strategy formulation, strategy content and performance: An empirical analysis. Public Management Review, 11(1): 1-22. http://dx.doi.org/10.1080/14719030802489989.

Andrews, R., G.A. Boyne, R.M. Walker, 2006. Strategy content and organizational performance: An empirical analysis. Public Administration Review, 66(1): 5263.

Andrews, R., M.J. Beynon, E. Genc, 2017. Strategy Implementation Style and Public Service Effectiveness, Efficiency, and Equity. Administrative Sciences, 7(1): 4.

Armstrong, J.S., 1982. The value of formal planning for strategic decisions: Review of empirical research. Strategic management journal, 3(3): 197-211.

Athapaththu, H.K.S.H., 2016. An overview of strategic management: An analysis of the concepts and the importance of strategic management. International Journal of Scientific and Research Publications, 6(2): 124. ISSN 2250-3153 www.ijsrp.org.

Azahari Ramli, M.Z., M. Mustafa, R.Z. Yusoff, 2017. SP and Organizational Performance in the Public Sector: A Study of Local Government in Aceh, Indonesia. The Social Sciences, 12(6): 902-906.

Boyne, G., 2001. Planning, performance and public services. Public administration, 79(1): 73-88.

Boyne, G.A., J.S. Gould-Williams, J. Law, R.M. Walker, 2004. Problems of rational planning in POs: An empirical assessment of the conventional wisdom. Administration \& Society, 36(3): 328-350.

Boyne, G.A., R.Z. Walker, 2010. SM and public service performance: The way ahead. Public Administration Review, 70(1): 185-192.

Bryson, J.M., 1999. SM in public and voluntary services: A reader. Amsterdam: Netherland: Pergamon.

Bryson, J.M., 2004. SP for public and nonprofit organizations: A guide to strengthening and sustaining organizational achievement. John Wiley \& Sons.

Bryson, J.M., 2011. SP for public and nonprofit organizations: A guide to strengthening and sustaining organizational achievement (4. ed). Hoboken N J: John Wiley \& Sons.

Bryson, J.M., 2018. Strategic planning for public and nonprofit organizations: A guide to strengthening and sustaining organizational achievement. John Wiley \& Sons.

Bryson, J.M., B.C. Crosby, J.K. Bryson, 2009. Understanding SP and the formulation and implementation of strategic plans as a way of knowing: The contributions of actor-network theory. International Public Management Journal, 12(2): 172-207.

Butnaru, G.I., C. Balcan, 2012. Characteristics of SM in innovation in the field of hotel services in Romania. International Journal of Academic Research in Business and Social Sciences, 2(10): 428.

Debarliev, S., M. Trpkova, 2011. SP practice in transition economies: Empirical evidence from the Macedonian context. Business and Economic Horizons, 4(1): 27-39.

Dudin, A.Y., 2013. Challenges facing the application of SM in Arabic business organizations: The case of Telecom Sector in Jordan. European Journal of Social Sciences, 37(1): 111-120

Durh, A.E., N.M. Jaradat, 2014. The fundamentals of strategic management; a systemic application approach. Amman, Jordan: Dar-Wael Publisher.

Edwards, L.H., 2012. SP in local government: Is the promise of performance a reality? (Doctoral dissertation, Georgia Institute of Technology and Georgia State University, Atlanta, GA, USA). Retrieved from http://scholarworks.gsu.edu/cgi/viewcontent.cgi?article=1037\&context=pmap_diss .

Elbanna, S., 2013. Processes and impacts of strategic management: Evidence from the public sector in the United Arab Emirates. International Journal of Public Administration, 36(6): 426-439.

Elbanna, S., R. Andrews, R. Pollanen, 2016. SP and implementation success in public service organizations: Evidence from Canada. Public Management Review, 18(7): 1017-1042.

Elbanna, S., Y. Fadol, 2016. An analysis of the comprehensive implementation of strategic plans in emerging economies: The United Arab Emirates as a case study. European Management Review, 13(2): 75-89.

Galloway, I.D., 1990. SM in public sector research organizations: a critical review. International Journal of Public Sector Management, 3(1).

Gause III, F.G., 2011. Why Middle East studies missed the Arab Spring: The myth of authoritarian stability. Foreign Affairs, 81-90.

Gazawi, M.S., 1996. Alwjeez fee altndeemalseyasiwaldustory fee almamlkaalordoniaalhashimia] Brief in political and constitutional organizational system in the Hashemite kingdom of Jordan (5th edition) Amman, Jordan. Dar Al-Thaqafa.

Guyadeen, D., 2017. Evaluation in Planning: An Investigation into Plan Quality and its Application to Official Plans in the Ontario-Greater Golden Horseshoe (GGH) Region. Retrieved from: https://uwspace.uwaterloo.ca/handle/10012/11832.

Harahsheh, M.J., R. Alhbees, 2010. [jkeematherdamjalfg]dhjfethseenalkdamataljtmaehfeekleemalshmal] The evaluation of municipalities effect on social services improvement in the Northern Region. (master's thesis). Al- Balqa' Applied University (BAU), Salt. Jordan.

Höglund, L., F. Svärdsten, 2015. SM in public sector-challenges in theory and practice. In Nordic Academy of Management Conference. Conference paper. Retrieved from:https:// www.researchgate.net/publication /284730974_Strategic_Management_in_Public_Sector_-_Challanges_in_Theory_and_Practice.

Hunger, J.D., T.L. Wheelen, 2003. Essentials of strategic management. New Jersey: Prentice Hall.

Hunger, J.D., T.L. Wheelen, 2011. Essentials of SM (5th ed). Uper Saddle River, NJ: I. Pearson Education Ed. Vol. 
Jaradat, A.S., M. Taamnh, 2005. Takeem athar amlyat aldamj ala edaa albaldyat ajkubra fee alardn ( draseh mydaneh mnwjhat nader alamleen walmuatneen fee ekleemalshmal ). Evaluation the Impact of Amalgamation on the performance of great municipalities (empirical study from local employees and citizens perspective in the Northern Region). (master's thesis). Yarmouk University, Irbid. Jordan.

Johnsen, A., 2017. Impacts of SP and management in municipal government: an analysis of subjective survey and objective production and efficiency measures in Norway, Public Management Review, doi: 10.1080/14719037.2017.1285115.

Klyla, M., 2013. [Aladarah almahleyah watatbegatoha fi kl mn Alardon, Bretania,Fransa w Meser].Local Administration and its Application in Jordan, UK, France, and

Ktameen, A., 2009. [Aledarh alsratejeh mfaheem whalat tatbekyh] SM concepts and aplications cases. Amman, Jordan. Dar Majdalawi Pub.

Ma'ani, A.O., M.O. Abo-faris, 1995. [ Ndaryat aledarh almhlyah wttbekatuha fee almmlkh alurdonyh alhashemiah] The local governance theory and its applications in the Hashemite Kingdom of Jordan. Amman, Jordan. National Library Department.

Ma'ayta, Z., 2016. Activating the role of Jordanian municipalities as enablers of economic growth. Retrieved from: https://medium.com/@USAIDLENS/activating-the-roleof-jordanian-municipalities-as-enablers-of-economic-growth-6587d3fd1091.

Magrebi, A., 1999. [ Aledart alestrategeah: Almowjha thdyat alkarn alwahd waleshreen] SM: Confrontation Challenges of the 21st Century. Cairo: Egypt. Nile Publishing Group. ISBN: $9775919010,9789775919014$.

Mansur, Y., 2014. Local development: distortions and challenges. Alghad Newspaper. Retrieved From http://www.alghad.com/articles/839638.Marin, S. C. (2016). SM in Public Administration. Risk in ontemporary Economy, 187-191.

Meier, K.J., L.J. O'Toole J, G.A. Boyne, R.M. Walker, 2006. SM and the performance of POs: Testing venerable ideas against recent theories. Journal of Public Administration Research and Theory, 17(3): 357-377.

Mercer, J.L., 1991. SP for public managers. Westport, CT: Greenwood Publishing Group, Int.

Miles, R.E., C.C. Snow, A.D. Meyer, H.J. Coleman, 1978. Organizational strategy, structure, and process. Academy of Management Review, 3(3): 546-562.

Mintzberg, H., 1987. The strategy concept I: Five Ps for strategy. California Management Review, 30(1): 11-24.

Momny, M.F., A.M. Edrees, 2002. [ Aslah al-hukm al-mhli fi Al-aurdn: Halat al-bladeat al-kubra fee al-shmsal] Local Government Reform: A case of the largest municipalities in the North region. (master's thesis). Al-albeit University, Mafraq. Jordan.

Mugenda, A., O. Mugenda, 2003. Research methods; Quantitative and Qualitative approaches, ACTS press, Nairobi.

Musa, S.M., N.B. Sheen, 2017. [Aledara alestratejeh waldaa almfaheem wkmathj alkias drasst halah tdbeekia bastkdam btaket aleda almtwazn] SM and performance; Concepts and measurement models a study of the practical use of balance scoreboard. Amman, Jordan. Dar-Al-Majdalawi Pub.

Omar, K., 2017. Ajlun residents demand repayment of municipalities troubled debts. Alghad Daily Newspaper. Retrieved from -بكان-بطالبون-بسداد-ديون-بلديات-عجلون المتعثرة-http://www.alghad.com/articles.

Organization for Economic Co-operation and Development (OECD), 2017).Towards a new partnership with Citizens: Jordan's decentralization reform. Amman, Jordan. Retrieved from: http://dx.doi.org/10.1787/9789264275461-en.

Poister, T., G. Streib, 1999. SM in the public sector: Concepts, models, and processes. Public Productivity \& Management Review, 22(3): 308-325. doi: $10.2307 / 3380706$

Poister, T.H., G. Streib, 2005. Elements of SP and management in municipal government: Status after two decades. Public administration review, 65(1): 45-56.

Poister, T.H., L.H. Edwards, O.Q. Pasha, J. Edwards, 2013. Strategy formulation and performance: Evidence from local public transit agencies. Public Performance \& Management Review, 36(4): 585-615.

Poister, T.H., O.Q. Pasha, O.Q. Edwards, 2013. Does performance management lead to better outcomes? Evidence from the US public transit industry. Public Administration Review, 73(4): 625-636.

Rasche, A., 2007. The paradoxical foundation of strategic management. Hamburg, Germany: Springer Science \& Business Media.

Rudolf, S.C., S.R. Grădinaru, 2017. The quality and implementation of local plans: An integrated evaluation. Environment and Planning B: Urban Analytics and City Science, 2399808317737070.

Saif, E., K. Suliman, N.W. Taal, 2004. [Albaldeeat: Dhaaf alastratejeah wa hymanet almrhalyah] Municipalities: Weak strategy and stage dominated. Amman, Jordan: Jordan University Strategic Study Center.

Seasons, M., 2003. Monitoring and evaluation in municipal planning: Considering the realities. Journal of the American Planning Association, 69(4): 430-440.

Shah, 2006. Local governance in developing countries., Washington D.C.: The World Bank.

Shuqair, H.I., D. Abdel-Aziz, 2015. Efficient and strategic resource allocation for sustainable development in Jordan. $J$ ArchitEng Tech, 4(1): 1-7. doi:10.4172/2168-9717.1000138.

Walker, R.M., 2013. SM and performance in POs: findings from the Miles and Snow framework. Public Administration Review, 73(5), 675-685.

World Bank executives are briefed on the challenges facing Jordan, 2017. Alrai Daily Newspaper, 1-2.

Yassin. G.S., 2011. [Aledara Alestratejeh]. Strategic Management. Amman, Jordan: Al Yazori publishing House. 